OPEN ACCESS

Edited by:

Kirsten K. Ness,

St. Jude Children's Research Hospital,

United States

Reviewed by:

Laura Gilchrist,

St. Catherine University, United States

David Mizrahi,

University of New South

Wales, Australia

*Correspondence:

Jörg Faber

faber@uni-mainz.de

${ }^{\dagger}$ These authors share first authorship

Specialty section:

This article was submitted to

Pediatric Oncology

a section of the journal

Frontiers in Pediatrics

Received: 04 December 2019

Accepted: 20 April 2020

Published: 05 June 2020

Citation:

Stössel S, Neu MA, Wingerter A, Bloch W, Zimmer P, Paret C, Malki KE, Baumann FT, Russo A, Henninger N,

Lehmann N, Otto $\mathrm{H}$ and Faber $J$ (2020) Benefits of Exercise Training for Children and Adolescents Undergoing Cancer Treatment: Results From the Randomized Controlled MUCKI Trial.

Front. Pediatr. 8:243.

doi: 10.3389/fped.2020.00243

\section{Benefits of Exercise Training for Children and Adolescents Undergoing Cancer Treatment: Results From the Randomized Controlled MUCKI Trial}

\author{
Sandra Stössel ${ }^{1 \dagger}$, Marie A. Neu ${ }^{1 \dagger}$, Arthur Wingerter ${ }^{1}$, Wilhelm Bloch ${ }^{2}$, Philipp Zimmer ${ }^{3}$, \\ Claudia Paret ${ }^{1}$, Khalifa El Malki ${ }^{1}$, Freerk T. Baumann ${ }^{4}$, Alexandra Russo', \\ Nicole Henninger ${ }^{1}$, Nadine Lehmann ${ }^{1}$, Henrike Otto ${ }^{1}$ and Jörg Faber ${ }^{1 *}$ \\ ${ }^{1}$ Center for Pediatric and Adolescent Medicine, Childhood Cancer Center, University Medical Center Mainz, Mainz, Germany, \\ ${ }^{2}$ Department of Molecular and Cellular Sport Medicine, Institute of Cardiovascular Research and Sports Medicine, German \\ Sport University Cologne, Cologne, Germany, ${ }^{3}$ Institute of Sport and Sport Science, Technical University of Dortmund, \\ Dortmund, Germany, ${ }^{4}$ Department I of Internal Medicine, Center of Integrated Oncology Köln Bonn, University Hospital of \\ Cologne, Cologne, Germany
}

Objective: In cancer patients, the impairment in muscle function is a frequently observed phenomenon. However, comprehensive evaluation of the effect of exercise training on muscle function in childhood cancer patients (CCPs) is sparse and therefore investigated in the MUCKI trial.

Study Design: In the randomized controlled MUCKI trial, CCPs during intensive cancer treatment and aged 4-18 years were recruited. Eligible patients were enrolled soon after diagnosis as long as they were physically and mentally able to participate in exercise testing and training. Patients of the exercise group $(n=16)$ participated in average 2.7 \pm 1.2 times per week in a combined resistance and endurance training with moderate exercise intensity, for a time period of $8.0 \pm 2.1$ weeks, while patients of the control group $(n=17)$ received usual care. Leg strength was evaluated as the primary endpoint. Secondary endpoints were 6-min walk performance, arm strength, body composition, fatigue, and health-related quality of life.

Results: Comparisons of pre- and post-intervention results were evaluated by baseline and stratification criteria adjusted analysis and showed positive effects for the exercise group regarding leg strength $\left[F_{(1,20)}=5.733 ; p=0.027^{*} ; \eta_{\mathrm{p}}^{2}=0.223\right]$, walking performance $\left[F_{(1,25)}=4.270 ; p=0.049^{*} ; \eta_{p}^{2}=0.146\right]$, fatigue $\left[F_{(1,13)}=8.353\right.$; $\left.p=0.013^{*} ; \eta_{\mathrm{p}}^{2}=0.391\right]$, self-esteem $\left[F_{(1,6)}=6.823 ; p=0.040^{*} ; \eta_{\mathrm{p}}^{2}=0.532\right]$, and self-reported strength and endurance capacity $\left[F_{(1,6)}=6.273 ; p=0.046^{*} ; \eta_{p}^{2}=0.511\right]$. No significant differences were found for the other parameters. 
Conclusion: Within one of the first randomized controlled trials, the present study provides evidence for a positive effect of combined training in CCPs during intensive cancer treatment. Further research is needed to confirm these results and to evaluate their clinical impact.

Clinical Trial Registration Number: NCT02612025.

Keywords: resistance training, endurance training, physical activity, pediatric oncology, muscle strength

\section{INTRODUCTION}

Skeletal muscle dysfunction is a commonly observed phenomenon in cancer patients (1). The disease itself and also its treatment negatively affect skeletal muscle strength and mass and lead to a reduced physical activity (PA) level, which further exacerbates skeletal muscle impairment $(2,3)$. However, exercise intervention studies in adult cancer patients have shown the effectiveness of physical exercise to increase patients' muscle mass and strength during and after medical treatment. This increase was associated with a significant improvement in patients' quality of life and with a reduction of frequently observed side effects, including reduced whole-body muscle mass and fatigue $(4,5)$. Strength and endurance training are recommended to generate positive effects on muscle function (3).

In children and adolescents suffering from cancer, lower limb muscle function seems to be more affected than upper limb muscles $(6,7)$. In children suffering from acute lymphoblastic leukemia, an impairment in leg muscle strength was observed within 7-10 days after diagnosis (8). In survivors of acute lymphoblastic leukemia during childhood, decreased muscle mass as well as impaired leg muscle strength and mobility deficits were revealed, and it is presumed that this may reduce the ability to participate in PA and lead to further fitness deficits (6). For adult cancer patients, exercise guidelines were developed by the American College of Sports Medicine in 2019 (9). For childhood and adolescent cancer patients (CCPs), specific training programs need to be established that are adapted to the CCPs' needs regarding their mental and physical development, the specific entities of childhood cancer and their social environment. Furthermore, the different entities of childhood cancer being associated with specific requirements and restrictions need to be considered, and training conditions need to be adjusted individually. Recent reviews and metaanalysis showed that the level of evidence for exercise training efficiency in CCPs during intensive cancer treatment is low, and further randomized controlled trials to analyze exercise training in pediatric cancer were requested (10-12).

For the MUCKI trial (clinical trial registration number: NCT02612025), a specific and individualized combined strength and endurance exercise program was designed for CCPs.

\footnotetext{
Abbreviations: 6MWT, 6-min walk test; BIA, bioelectrical impedance analysis; CCPs, childhood and adolescent cancer patients; CG, control group; EG, exercise group; HRQOL, health-related quality of life; PA, physical activity; RPE, rate of perceived exertion.
}

Regarding the above-described muscle function impairments especially in the lower limbs in pediatric cancer patients, the primary outcome of the present study was to investigate whether the adapted exercise program can improve leg muscle strength and other physical and mental parameters (secondary outcomes) in CCPs during intensive cancer treatment.

\section{MATERIALS AND METHODS}

The MUCKI trial was carried out at the Childhood Cancer Center at the Center for Pediatric and Adolescent Medicine at the University Medical Center Mainz in Germany. All procedures performed in this study are in accordance with the ethical standards of the institutional research committee [approved by ethics review committee of the Rhineland-Palatinate Chamber of Physicians, trial reference number 837.059.15 (9827)] and with the 1964 Declaration of Helsinki and its later amendments. Written informed consent was obtained from the legal guardians in the case of minor participants and from all study participants older than 6 years of age.

\section{Participants}

Patients were eligible if they were at least 4 years of age and treated with chemotherapy and/or radiotherapy for an oncologic disease according to the International Classification of Childhood Cancer at the University Medical Center Mainz in Germany. Patients were excluded in case of functional and/or cognitive limitations which might confine performance during training, orthopedic condition which hinders adequate participation in exercise training, heart failure (NYHA III and IV), partial or global respiratory failure, symptomatic coronary disease, serious therapy-refractory hypertonia, sustainable thrombocytopenia $<10,000 / \mu \mathrm{l}$, hereditary or acquired thrombocytopenia or coagulation disorder, uncontrolled seizure, central nervous system metastases, and any other medical or psychological condition which did in the physician's opinion not allow participation in sport activity or which might limit performance during testing or training.

\section{Procedure}

A treating oncologist enrolled children and adolescents meeting the inclusion and exclusion criteria soon after diagnosis as long as they were physically and mentally able to participate in exercise testing and training. After a pre-intervention exercise test, the study participants were randomly assigned in a 1:1 ratio in either an exercise group (EG) or a control group (CG). 
Beyond usual medical care, participants from the EG took part in a 6- to 8-week-long supervised exercise program, whereas patients from the CG received usual care without a supervised exercise intervention. A post-intervention exercise test took place for participants of both study groups about 6-8 weeks after pre-intervention testing. All exercise tests were programmed to take place prior to the start of a new cancer therapy cycle on condition of hematologic recovery in order to ensuring maximum comparability.

\section{Randomization}

Stratified randomization was used to equally allocate (1:1) patients in the EG and CG. Following the minimization procedure according to Pocock and Simon (13), tumor entity (acute leukemia or t-cell lymphoma/central nervous system tumor/others), age (at least 12 years of age/younger than 12 years of age), sex, and physical performance status assessed by Lansky score at diagnosis (higher than 50/equal or lower than 50) were used as stratification factors. Computerized randomization software [Randomization In Treatment Arms (RITA) Version 1.31, StatSol Lübeck, Germany] was used for this purpose. The investigator, therapists, and patients were not blinded to group assignment as it was apparent to which patients the exercise intervention was provided.

\section{Sample Size}

Prior to the MUCKI trial, power calculation was not achievable due to the lack of reliable data from previous studies. Based on an interim analysis after inclusion of 20 patients in the MUCKI trial, power calculation indicated that a sample size of 35 patients was needed to determine intergroup differences in leg muscle strength (power set at an $80 \%$ level, two-sided two-sample $t$-test set at a 0.05 significant level). The software $G^{*}$ Power 3.1 was used for this calculation.

\section{Study Parameters and Methods}

All of the following described measurements were undertaken at pretesting and posttesting except the PA questionnaire, which was solely filled out at the pretest. Contraindications for exercise testing and training were fever/body temperature of $>38.0^{\circ} \mathrm{C}$; acute infection/sepsis; severe pain; acute bleeding; thrombocytes $<20 / \mathrm{nl}$ (thrombocytes $<50 /$ nl no strength testing); nausea/vomiting/diarrhea; resting heart rate $>130 /$ min $(<12$ years of age) and $>100 /$ min ( $\geq 12$ years of age); cardiovascular disorders; ongoing mediastinal irradiation; vertigo; severe ataxia; disturbance of consciousness; other medical or psychological conditions denying medical clearance by the treating oncologist; and patient or parent denying participation.

\section{Anthropometric Data and Medical Data}

Anthropometric data on body height and weight were measured using standardized methods and equipment. Medical data, such as information on diagnosis and treatment, were obtained from the patient records.

\section{Muscle Strength}

Knee strength and elbow flexor strength were measured with a handheld dynamometer (CITEC handheld dynamometer, type
3002, CIT Technics, Haren, Netherlands). Maximum isometric contraction was evaluated using the "break technique" described by Beenakker et al. (14). The highest value out of three repetitions was counted as the maximum strength and kept for analysis. The handheld dynamometry method showed high validity $(r=0.74$ and $r=0.98)$ and moderate intertester reliability $(r=0.42$ to $r=0.73$ ) in healthy and chronically ill children and adolescents $(15,16)$ and is considered as a reliable and valid instrument for muscle strength assessment in a clinical setting compared to the gold standard isokinetic dynamometry (17). In the MUCKI trial, only two exercise practitioners performed the strength test throughout the entire study time to decrease interrater variability. The minimally important difference of this measurement is not known for the healthy population or for cancer patients. However, Vaidya et al. (18) described a minimally important difference of 7.5 Newton for fixed dynamometer testing in patients with chronic obstructive pulmonary disease.

\section{Walking Performance}

To evaluate walking performance, the 6-min walk test (6 MWT) was performed according to the test protocol from Geiger et al. (19) for 6 MWT in children. The 6 MWT was conducted on a 15$\mathrm{m}$-long course in a hospital corridor. The test showed moderate validity $(r=0.44$ and $r=0.76)$ and high reliability in healthy and chronically ill children and adolescents $(r=0.90$ und $r=0.94)$ $(20,21)$.

\section{Body Composition}

Bioelectrical impedance analysis (BIA EgoFit, 2010, Germany) was used to measure phase angle (phA). The phA is a wellestablished indicator for cellular health where higher phA values signify better quality of soft tissue (22). In healthy adults and cancer patients, the phA correlated to overall mortality, clinical outcome, PA level and exercise performance (22). The validity of phA measurement was evaluated in healthy normal-weight and underweight children, where phA was correlated to body weight and arm circumference ( $r=0.818$ and $r=0.901)$ (23). Measurements with the BIA method at $50 \mathrm{kHz}$ are known for high reliability (age-dependent $p=0.003$ to 0.001 ) (24) and were performed in the MUCKI trial on the right body side for the whole body, arm, and leg evaluations.

\section{Fatigue}

To evaluate fatigue level, the German language questionnaire PedsQL 3.0 Multidimensional Fatigue Scale (25) was used. It consists of 18 items about general fatigue, sleep/rest fatigue, and cognitive fatigue. Both child and parent proxy questionnaires were filled out.

\section{Health-Related Quality of Life (HRQOL)}

The German-language KINDL questionnaire (26) was filled out by the study participants to evaluate HRQOL. It contains 30 items concerning physical and mental well-being, self-esteem, family, friends, and functionality in daily life. In addition, cancer-specific questions about the disease and treatment were posed. Both child and parent proxy questionnaires were filled out. 


\section{PA Questionnaire}

The level of PA prior to disease onset (before any signs or symptoms of the disease were present) was determined by the German MoMo questionnaire (27). The questionnaire consists of items asking for PA level and intensity in daily life, at kindergarten/school, and in sports clubs. The information provided by the questionnaire was used to adapt the training program to individualize the exercise training. Adolescents completed the questionnaire on their own, whereas parents helped younger children to fill it out.

\section{Semi-Structured Interview}

In a semi-structured interview, patients' PA behavior was evaluated. For this, patients rated their PA level on a 10-stage scale and that for children under the age of 8 years on a threestage scale, with 1 meaning no PA and 10 signifying a very high PA level. Further, patients were asked how many hours they spent out of bed during (a) homestays and (b) hospitalization (28). Barriers and motivation factors for PA were evaluated by open questions. Patients from the EG were asked at the postintervention test to evaluate the exercise program in which they had participated during the trial.

\section{Intervention}

Patients from the EG participated in a supervised exercise training for 6-8 weeks during intensive cancer treatment. The training took place in the inpatient and outpatient clinics as well as in patients' home during outpatient stays. Most of the exercise sessions were supervised by an exercise scientist. Occasionally, such as on weekends, patients and their parents trained on their own following exercise recommendations from the exercise scientist.

The aim was to accomplish three weekly training sessions of 45-60 min each. However, training workload was adapted to the patient's exercise habits and fitness and health condition. Training mainly consisted of age-appropriate and moderateintensity endurance and strength training. Additionally, active games and balance and stretching exercises were performed. Endurance training comprised mainly ergometer training, aerobic exercises, and walking exercises. Strength training was mostly performed on a cable pulley machine, with mini dumbbells, elastic bands, or body weight. The exercises were surrounded by playful games in order to enhance compliance especially for younger children. Compliance for training was rated by the supervising exercise practitioner at the end of each session on a 6-point scale with 1 presenting the highest compliance.

A training session started with playful exercises such as lowintensity ballgames, followed by moderate-intensity endurance and muscle strength exercises which were often combined with coordination and balance exercises. A cooldown at the end of each session consisted of light-intensity playful exercise, relaxation, and stretching.

Exercise intensity was rated as moderate if at least two of the following criteria were fulfilled: (1) $60-75 \%$ of estimated maximum heart rate (29), (2) a score of 12 to 13 on the Borg scale RPE6-20 (30), of 11-12 for playful activities such as exergaming
(31), and at medium level on a child-adapted three-level scale (32), (3) strength exercises were rated as moderately intense if no more than two to three more repetitions could be realized from the patient with correct technical execution (progression to no more possible further repetition was aimed over the weeks of training) $(33,34)$, and (4) a rating of the intensity level by the supervising exercise scientist depending on breathing rate, sweating, and other signs of exhaustion. The goal was to perform 15-20 min of moderate endurance training per session as well as 6-10 min of leg strength training. For homestays, the participants and parents of younger children were trained to use the Borg scale and to use a provided wrist-worn heart rate monitor (Polar A360, Electro, Kempele, Finland) to control the exercise intensity. Additionally, heart rate was collected manually to detect eventual measuring errors of the wrist-worn heart rate monitor (35).

A $20-\mathrm{m}^{2}$-sized exercise room was available for training in the children's hospital. Exercise sessions were conducted with a single patient or a patient group and could be accompanied by parents, siblings, or friends.

The equipment used for training met hygienic requirements needed in the oncological setting, was transportable to the patient's room, and was available for different body sizes. Medical clearance to participate in exercise was obtained prior to any exercise test or session.

\section{Statistical Methods}

Group-time interaction was evaluated by analysis of covariance (ANCOVA) adjusted for the baseline value and stratification criteria (i.e., age, sex, tumor entity, and Lansky score at diagnosis). Results from ANCOVA are reported as $p$ - and $F$ values, degrees of freedom (df), and effect size (partial $\eta^{2}$ ). Pearson $r$ was used to evaluate correlations. The level of significance was set at $p \leq 0.05$. Statistical analysis was performed using IBM SPSS Statistics software Version 23. All available data were included in the statistical analysis referring to the intentionto-treat approach with respect to the original study group assignment and regardless of the patient's participation rate in the exercise intervention. Only completed outcome measures were included in the analysis, and no attempt to impute missing data was made.

\section{RESULTS}

Enrollment of study patients took place from December 2015 to September 2018. After screening for inclusion and exclusion criteria, 18 patients were randomized to the EG and 17 to the CG. In the EG, there was one dropout due to lack of motivation for participation in exercise training and another dropout due to unstable mental condition prohibiting participation in regular exercise training and testing. The primary outcome could not be determined in four participants due to leg pain and in another participant because of a technical problem with the dynamometer. Additional information concerning the progress of all participants during the trial is shown in the flow diagram (Figure 1) adapted from the CONSORT 2010 Statement (36). Patient characteristics are presented in Table 1. At baseline, patients achieved $53.25 \pm 33.21 \%$ of leg muscle strength and 


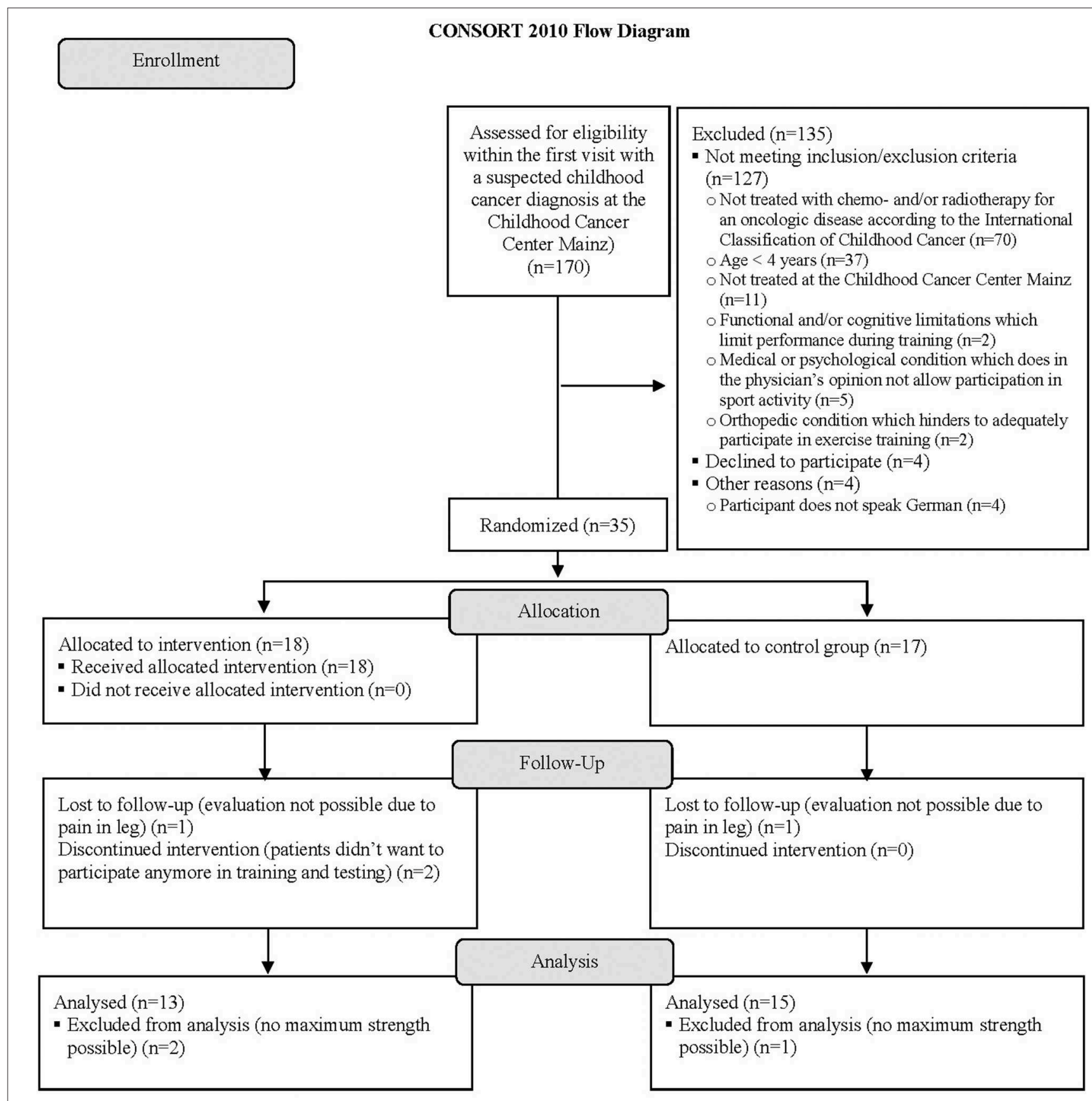

FIGURE 1 | Flow diagram of the trial progress. Adapted CONSORT 2010 flow diagram (36) of the progress through the phases of the randomized controlled MUCKI trial of the exercise group and control group regarding the primary outcome knee flexor strength.

$62.30 \pm 14.31 \%$ of arm muscle strength compared to norm values (14). Results from BIA revealed significantly lower phA in patients compared to norm values $(37)\left(p=0.000^{*} ; d=1.05\right)$.

Comparing intergroup baseline results after the adjustment for the stratification criteria, only leg muscle strength was significantly different between the two groups with lower strength in the $\mathrm{EG}\left(p=0.002^{*} ; d=0.378\right)$.
On average, each patient performed $2.7 \pm 1.2$ supervised exercise sessions per week during an $8.0 \pm$ 2.1-week-long intervention period. One session lasted $48.1 \pm 10.1 \mathrm{~min}$, from which most of the time was spent for endurance (18.1 $\pm 9.1 \mathrm{~min}$ in total including $10.4 \pm 4.5 \mathrm{~min}$ of moderate intensity) and leg strength exercises (16.7 $\pm 8.4 \mathrm{~min}$ in total including $10.5 \pm 3.3 \mathrm{~min}$ of moderate intensity). Most 
TABLE 1 | Characteristics of the study population.

\begin{tabular}{lccc}
\hline & $\begin{array}{c}\text { Exercise group } \\
(\boldsymbol{n}=\mathbf{1 6})\end{array}$ & $\begin{array}{c}\text { Control group } \\
(\boldsymbol{n}=\mathbf{1 7})\end{array}$ & $\boldsymbol{p}$-value \\
\hline Age (year) & $10.6 \pm 5.19$ & $11.4 \pm 4.25$ & 0.476 \\
& $(4.1-17.3)$ & $(5.1-17.7)$ & \\
Sex ( $n$ boys) & 10 & 10 & - \\
Body height (cm) & $144.4 \pm 27.5$ & $146.0 \pm 20.5$ & 0.849 \\
Body weight (kg) & $42.3 \pm 19.8$ & $44.1 \pm 25.4$ & 0.961 \\
BMl (kg/m²) & $19.1 \pm 3.5$ & $19.2 \pm 5.7$ & 0.831 \\
BMl (z-score) & $-0.07 \pm 0.75$ & $0.07 \pm 1.22$ & 0.704 \\
Lansky score at diagnosis $<50(n)$ & 2 & 1 & - \\
Tumor entities ( $n$ ) & & & - \\
$\quad$-Leukemia/T-cell-lymphoma & 8 & 7 & \\
-CNS-tumor & 2 & 2 & \\
$\quad$-Others & 6 & 8 & \\
Time from pretest to posttest (week) & $8.0 \pm 2.1$ & $8.4 \pm 2.6$ & 0.687 \\
& $(5.1-12.1)$ & $(5.4-14)$ & \\
Time from diagnosis to pretest & $7.3 \pm 3.7$ & $5.9 \pm 3.0$ & 0.354 \\
(week) & & & \\
PA level from the MoMo & $89.0 \pm 90.9 \%$ & $101.4 \pm 49.0 \%$ & 0.628 \\
questionnaire & of norm & of norm & \\
\hline
\end{tabular}

Data are mean $\pm S D$, n or range; CNS, central nervous system; $P A$, physical activity; data of the two dropped-out participants are not included in the table.

TABLE 2 | Overview of training settings in the MUCKI trial.

\begin{tabular}{lc}
\hline Setting of the training session & Number of sessions in total $(\boldsymbol{n})$ \\
\hline Inpatient setting & $9.3 \pm 3.9$ \\
Outpatient setting & $2.1 \pm 1.4$ \\
Supervised training in patient's home & $4.9 \pm 4.9$ \\
Self-administered training & $3.4 \pm 5.3$ \\
\hline
\end{tabular}

Results as means $\pm S D$.

training sessions were supervised, and few sessions were selfadministered (Table 2). Compliance for training was rated 1.7 \pm 0.5 on an above-explained 6-point scale. Exercise scientists supervised $85.1 \pm 16.7 \%$ of all sessions performed, and the remaining sessions were conducted by the patients on their own. The leading cause of cancelation or postponing of exercise sessions were medical reasons, representing 53.7\% (i.e., infections/cough/dental inflammation 13.6\%; reduced platelet count requiring transfusion $12.2 \%$; severe nausea/vomiting $6.8 \%$; fatigue/exhaustion $6.8 \%$; severe bone pain $2.7 \%$; others $7.5 \%$ ). Other reasons were lack of motivation for autonomous training not being supervised by an exercise scientist (15.0\%), lack of time/staff/room (14.3\%), lack of motivation for supervised training (4.8\%), parents refusing their child's participation in an exercise session (2.0\%), and other reasons (10.2\%).

Regarding muscle strength, ANCOVA revealed benefits for knee flexor strength in the EG $\left[F_{(1,20)}=5.733 ; p=0.027^{*}\right.$; $\left.\eta_{\mathrm{p}}^{2}=0.223\right]$ with no differences in arm flexor strength $\left[F_{(1,21)}=1.108 ; p=0.305\right]$ (Table 3). Additionally, walking performance investigated by the $6 \mathrm{MWT}$ showed positive grouptime interaction effects for the EG $\left[F_{(1,25)}=4.270 ; p=0.049^{*}\right.$; $\left.\eta_{\mathrm{p}}^{2}=0.146\right]$ (Table 3). Neither at the pretest nor at the posttest an intergroup difference was observed in maximally achieved heart rate or rate of perceived exertion (RPE). The heart rate in percent of age predicted maximum heart rates of $79.5 \pm 9.7$ $\%$ in the EG and $79.6 \pm 13.8 \%$ in the CG $(p=0.971)$ at the pretest and of $82.9 \pm 9.0 \%$ in the EG and $76.2 \pm 11.0 \%$ in the CG $(p=0.156)$ at the posttest. The RPEs were $9.6 \pm 3.9$ in the EG and $10.9 \pm 2.6$ in the CG $(p=0.415)$ at the pretest and $11.5 \pm 2.7$ in the EG and $8.6 \pm 5.7$ in the CG $(p=0.259)$ at the post-test. As mentioned in the Materials and Methods section, questionnaires for patient's fatigue and HRQOL were filled out by patients and their parents separately. Reasons for failed questionnaire completion were low compliance, lack of time, insufficient German speaking ability, and the absence of patient's parents on the examination day (Table 3). The patients' self-reported fatigue level was significantly decreased at the time of the posttest relative to the pretest in EG $\left(p=0.026^{*}\right.$; $d=1.11$ ), but not in CG. However, results from ANCOVA did not reveal significant differences in group-time interaction for the self-reported fatigue level. Patients' fatigue levels reported by their parents illustrate a positive effect of the exercise training $\left[F_{(1,13)}=8.353 ; p=0.013^{*} ; \eta_{\mathrm{p}}^{2}=0.391\right]$. HRQOL evaluated by the patients themselves suggested beneficial effects in the EG regarding the subscales self-esteem $\left[F_{(1,6)}=6.823 ; p=0.040^{*}\right.$; $\left.\eta_{\mathrm{p}}^{2}=0.532\right]$ and strength and endurance $\left[F_{(1,6)}=6.273\right.$; $\left.p=0.046^{*} ; \eta_{\mathrm{p}}^{2}=0.511\right]$. No significant group-time interactions were seen in patients' HRQOL reported by their parents. Moreover, no significant group-time interactions were found for the phA measured by BIA (Table 3). In the interview, patients from EG indicated higher PA levels than those from CG for the group-time interaction $\left[F_{(1,20)}=7.255 ; p=0.014^{*} ; \eta_{\mathrm{p}}^{2}=0.266\right]$, whereas no significant difference was reported regarding the time spent out of bed in the clinic as well as at home during homestays. Moreover, all patients of the EG reported that they had fun taking part in the exercise program and that they would recommend it to other patients. Furthermore, all of them would appreciate continuing to take part in the exercise offers during hospital stays.

Analysis revealed significant correlations between before and after changes from $6 \mathrm{MWT}$ and (a) three subscales from patients' self-reported HRQOL (i.e., physical well-being $r=0.751$; $p=0.003$; mental well-being $r=0.633$; $p=0.020$; self-esteem $r=0.597 ; p=0.024)$, (b) patients' self-esteem reported by their parents $(r=0.442 ; p=0.035)$, (c) patients' fatigue reported by their parents $(r=0.528 ; p=0.014)$. Regarding the other subscales of fatigue and HRQOL questionnaires, no correlations with the walking performance were found. Furthermore, no correlations were observed concerning before-after changes in leg strength and fatigue or HRQOL.

\section{Adverse Events}

No serious adverse events occurred during the, in total, 381 exercise and testing sessions. During walking exercises in testing and training sessions, three patients fell but without getting injured. Furthermore, light to moderate muscle soreness was experienced three times after testing sessions and four times after training. 
TABLE 3 | Results from pretests and posttests by group.

\begin{tabular}{|c|c|c|c|c|c|c|c|}
\hline & \multicolumn{3}{|c|}{ Exercise group } & \multicolumn{3}{|c|}{ Control group } & \multirow{2}{*}{$\begin{array}{c}\text { Interaction } \\
\text { p-value }\end{array}$} \\
\hline & Pretest & Posttest & $n$ & Pretest & Posttest & $n$ & \\
\hline \multicolumn{8}{|l|}{ Muscle strength } \\
\hline Knee flexor $(N)$ & $74.62 \pm 41.45$ & $89.62 \pm 45.99$ & 13 & $128.13 \pm 49.78$ & $115.60 \pm 44.48$ & 15 & *0.027 \\
\hline $\operatorname{Arm}$ flexor $(N)$ & $92.36 \pm 41.18$ & $93.86 \pm 42.39$ & 14 & $103.80 \pm 45.27$ & $95.53 \pm 37.49$ & 15 & 0.305 \\
\hline \multicolumn{8}{|l|}{ Walking performance } \\
\hline $6 \mathrm{MWT}(m)$ & $470.66 \pm 179.75$ & $515.29 \pm 136.18$ & 16 & $531.82 \pm 81.52$ & $517.32 \pm 54.53$ & 17 & ${ }^{\star} 0.049$ \\
\hline \multicolumn{8}{|l|}{ Anthropometry } \\
\hline phA whole body $(\Omega)$ & $4.63 \pm 0.97$ & $4.61 \pm 0.78$ & 12 & $5.12 \pm 0.68$ & $5.00 \pm 0.82$ & 17 & 0.180 \\
\hline phA leg $(\Omega)$ & $3.86 \pm 1.32$ & $3.79 \pm 1.07$ & 12 & $4.44 \pm 1.08$ & $4.21 \pm 1.07$ & 17 & 0.210 \\
\hline phA arm $(\Omega)$ & $4.25 \pm 0.65$ & $4.12 \pm 0.56$ & 12 & $4.65 \pm 0.60$ & $4.61 \pm 0.70$ & 17 & 0.158 \\
\hline Body mass (kg) & $39.33 \pm 18.89$ & $40.91 \pm 21.65$ & 13 & $44.07 \pm 25.44$ & $44.12 \pm 24.95$ & 17 & 0.149 \\
\hline BMl $\left(k g / m^{2}\right)$ & $18.63 \pm 3.47$ & $19.02 \pm 4.59$ & 13 & $19.23 \pm 5.70$ & $19.24 \pm 5.80$ & 17 & 0.416 \\
\hline \multicolumn{8}{|l|}{ Fatigue (total score) } \\
\hline Patient questionnaire & $70.55 \pm 17.43$ & $79.17 \pm 12.00$ & 7 & $71.18 \pm 18.14$ & $70.96 \pm 21.69$ & 11 & 0.327 \\
\hline Parent questionnaire & $63.00 \pm 21.98$ & $77.19 \pm 13.40$ & 9 & $61.57 \pm 18.87$ & $68.34 \pm 8.65$ & 12 & ${ }^{*} 0.013$ \\
\hline \multicolumn{8}{|l|}{ HRQOL (total score) } \\
\hline Patient questionnaire & $63.78 \pm 9.16$ & $68.75 \pm 9.46$ & 5 & $81.11 \pm 12.32$ & $77.73 \pm 14.70$ & 9 & 0.504 \\
\hline Parent questionnaire & $71.31 \pm 9.07$ & $71.03 \pm 11.80$ & 7 & $73.00 \pm 13.02$ & $70.53 \pm 12.99$ & 14 & ${ }^{*} 0.046$ \\
\hline \multicolumn{8}{|l|}{ Interview } \\
\hline PA level (scores 1-10) & $5.00 \pm 3.16$ & $6.89 \pm 1.80$ & 13 & $6.00 \pm 3.02$ & $4.87 \pm 3.21$ & 15 & ${ }^{*} 0.014$ \\
\hline Hours out of bed in clinic & $4.14 \pm 3.95$ & $2.64 \pm 1.60$ & 7 & $5.98 \pm 6.09$ & $5.14 \pm 5.58$ & 9 & 0.445 \\
\hline Hours out of bed at home & $9.36 \pm 4.53$ & $13.29 \pm 1.98$ & 7 & $7.17 \pm 3.95$ & $8.47 \pm 5.81$ & 9 & 0.099 \\
\hline
\end{tabular}

${ }^{*} p \leq 0.05$; data are mean $\pm S D$; $p h A$, phase angle; $H R Q O L$, health-related quality of life; $P A$, physical activity.

\section{DISCUSSION}

The MUCKI trial aimed to gain further knowledge about possible effects of exercise training in pediatric oncology, as the level of evidence in this field is rather low. Results from the MUCKI trial showed that combined resistance and endurance training adapted to the specific requirements of pediatric oncology leads to multiple benefits during intensive cancer treatment in a nonstem-cell transplant setting.

The present results revealed positive effects of exercise training on leg muscle strength, but not on arm muscle strength. This, however, can be explained by the fact that the resistance training performed during the MUCKI trial was focused on strengthening the leg muscles, so that an improvement in arm muscle strength could not be expected. Thus, the data from the MUCKI trial confirm that specific leg strength training leads to benefits in the trained muscles in CCPs. The results are in accordance with the study of Fiuza-Luces et al. (38), who observed positive effects on muscle strength following leg and arm training in pediatric patients during neoadjuvant treatment for solid tumors. Consequently, the results from the MUCKI trial indicate that benefits from specific training can also be achieved in pediatric patients with tumor entities other than solid tumors. Higher muscle strength was shown being related to an improved treatment tolerance in adult cancer patients (5) as well as to an increased quality of life in healthy children and adolescents (33). Hence, the present results in CCPs provide evidence for possible positive effects of specific training on muscle strength assuming benefits regarding patient's quality of life. Test failures in the MUCKI trial were mainly caused by leg pain. Future trials should consider failure reasons to increase the participation rate in muscle strength testing.

The MUCKI trial revealed that patients participating in exercise training improve their walking performance, which was accompanied by decreased fatigue and improved HRQOL. Substantiating the results of the present study, a positive association between walking performance and fatigue in pediatric cancer patients during intensive treatment was already observed by Braam et al. (39). Furthermore, better walking performance was associated with greater physical well-being in patients suffering from chronic obstructive pulmonary disease (40). The underlying mechanisms which are responsible for the benefits of exercise on fatigue and well-being are not completely understood to date. It is assumed that there might be direct mechanisms such as enhanced functional capacity and decreased inflammation, as well as indirect mechanisms such as improved sleep quality and decreased anxiety (41). In recent reviews and meta-analyses, it remains unclear whether training benefits on walking performance can be achieved in CCPs $(11,12)$. The present findings aim to increase the actual low level of evidence in this field. According to the present findings of the MUCKI trial, training of walking capacity seems to be worthwhile in order to attain benefits on walking performance, which come along with positive effects on fatigue 
and HRQOL. Further research into the underlying mechanisms is required.

In the present population, the phA derived from BIA was significantly lower compared to norm values. Reduced phA was shown being related to lower cellular health and higher morbidity and mortality $(22,42)$. In previous studies, phA was increased after an exercise training lasting 2-6 months in the elderly and in patients suffering from chronic obstructive pulmonary disease (43-46). However, no significant effect in group-time interaction regarding phA was found in the MUCKI trial. This may be due to measuring bias related to the BIA method, due to varying hydration status in cancer patients $(47,48)$, to the relatively short time of exercise intervention, or to an incapacity of CCPs to adapt to training on the cellular health level. Further research on potential benefits of training on body composition is of particular interest for CCPs, especially in view of attenuating the cachexia syndrome which is observed in 7-50\% of CCPs $(49,50)$.

Questionnaires investigating the level of fatigue and HRQOL in the MUCKI trial showed beneficial effects for EG in some of the total and sub-scores of the questionnaires. These results are in accordance with findings revealing benefits on fatigue and HRQOL in adult cancer patients $(51,52)$. The present results confirm the findings of Lam et al. (53) who observed benefits on fatigue and HRQOL after an exercise intervention lasting 6 months during childhood cancer treatment. As in CCPs, the evidence level in this field is low $(10,11)$ the present results provide important evidence for positive effects of exercise training on fatigue and HRQOL in CCPs. This is of particular interest, as no gold-standard treatment options are established so far to attenuate fatigue (54). However, the questionnaire response rate in the MUCKI trial was low due to the above-explained reasons. In future trials, higher sample sizes should therefore be considered, and additional time for the effortful questionnaire completion should be scheduled besides the PA testing sessions. In the present study, patients indicated that they had fun participating in the exercise training. Furthermore, compliance for the exercise training was high, and no serious adverse events did occur, indicating that the training of the present study was well accepted and tolerated by CCPs. One limitation of the MUCKI trial is the high variance of the data, which is attributed to the high heterogeneity of the study population regarding, for example, a wide range of age, tumor entities, and different medical treatment protocols. Nevertheless, this heterogenic cohort represents the population exercise professionals are confronted to in their daily practice in pediatric oncology.

Another potential limitation is the restricted interpretation of the training effect on leg muscle strength in the MUCKI trial because of the baseline difference in leg muscle strength between the EG and the CG. This may lead to an overestimation of the training effect (55). Further investigations using higher sample sizes are needed to perform subgroup analysis of more homogeneous populations. This would provide a deeper insight into training adaptation and thus allow further optimization of training efficiency in CCPs.

The interpretation of the results from the MUCKI trial is further limited by the small and heterogeneous sample.
Although a balanced allocation in both study groups with regard to the stratification factors was aimed within the MUCKI trial, the results need to be confirmed in higher sample sizes, allowing subgroup analysis to evaluate, for example, if different cancer treatments have impacts on the exercise efficiency. However, the heterogeneous sample allows us to put the experiences made in the MUCKI trial into practice as exercise professionals in pediatric oncology are confronted to such heterogeneous populations.

In the MUCKI trial, benefits on leg muscle strength during intensive cancer treatment were observed. Follow-up was not part of the study protocol. Impairments in leg muscle strength were detected during childhood cancer treatment, as well as in survivors after the treatment, as explained in the Introduction. Therefore, potential long-term effects of exercise training on muscle function in CCPs should be investigated in the future.

\section{Perspective}

The MUCKI trial was designed to gain new knowledge about adapted physical exercise in CCPs that might be considered to improve integrated health care in pediatric oncology. Within one of the first randomized controlled trials, this study illustrates the positive effects of exercise training on leg muscle strength in $\mathrm{CCPs}$ during intensive cancer treatment. The present findings can be used by exercise professionals to optimize the exercise training with CCPs. As adapted exercise provision is still rare in multidisciplinary pediatric cancer care and specialized staff and facilities to provide adapted exercise are often missing, these new data encourage further investigations on exercise training in pediatric oncology. In this perspective, the confirmation of the present results and the evaluation of their clinical impact are needed.

\section{DATA AVAILABILITY STATEMENT}

The datasets generated for this study are available on request to the corresponding author.

\section{ETHICS STATEMENT}

The study was approved by the ethics review committee of the Rhineland-Palatinate Chamber of Physicians, trial reference number 837.059.15 (9827). Written informed consent to participate in this study was provided by the participants' legal guardian/next of kin. Written informed consent was obtained from the legal guardians in the case of minor participants and from all study participants older than 6 years of age.

\section{AUTHOR CONTRIBUTIONS}

SS, MN, AW, WB, CP, KM, AR, NH, FB, PZ, and JF contributed to the conception and design of the study and contributed to the application for approval at the ethic committee. SS, MN, $\mathrm{AW}, \mathrm{WB}, \mathrm{CP}, \mathrm{KM}, \mathrm{AR}, \mathrm{NH}, \mathrm{HO}, \mathrm{FB}, \mathrm{PZ}$, and JF analyzed and interpreted the study data. SS and $\mathrm{MN}$ drafted the article. AW, WB, CP, KM, AR, NH, NL, HO, FB, PZ, and JF substantially revised the article. SS, $\mathrm{MN}, \mathrm{AW}, \mathrm{KM}, \mathrm{AR}, \mathrm{NH}$, and $\mathrm{HO}$ acquired 
the data. SS, MN, AW, KM, AR, NH, and $\mathrm{HO}$ recruited the study participants. JF handled funding and supervision.

\section{ACKNOWLEDGMENTS}

The authors sincerely thank all patients for participating in this study. Furthermore, we thank Nicole Ziegler for editing

\section{REFERENCES}

1. Christensen J, Jones L, Andersen J, Daugaard G, Rorth M, Hojman P. Muscle dysfunction in cancer patients. Ann Oncol. (2014) 25:947-58. doi: 10.1093/annonc/mdt551

2. Baumann FT, Schüle K, Fauser AA, Kraut L. Auswirkungen von Bewegungstherapie bei und nach Knochenmark-/Stammzelltransplantation. Deutsc Zeitschr Onkol. (2005) 37:152-8. doi: 10.1055/s-2005-918019

3. Gould DW, Lahart I, Carmichael AR, Koutedakis Y, Metsios GS. Cancer cachexia prevention via physical exercise: molecular mechanisms. J Cachexia Sarcopenia Muscle. 4:111-24. doi: 10.1007/s13539-012-0096-0

4. Stene GB, Helbostad JL, Balstad TR, Riphagen II, Kaasa S, Oldervoll LM. Effect of physical exercise on muscle mass and strength in cancer patients during treatment-a systematic review. Crit Rev Oncol Hematol. (2013) 88:573-93. doi: 10.1016/j.critrevonc.2013.07.001

5. Strasser B, Steindorf K, Wiskemann J, Ulrich CM. Impact of resistance training in cancer survivors: a meta-analysis. Med Sci Sports Exerc. (2013) 45:2080-90. doi: 10.1249/MSS.0b013e31829a3b63

6. Ness KK, Baker KS, Dengel DR, Youngren N, Sibley S, Mertens AC, et al. Body composition, muscle strength deficits and mobility limitations in adult survivors of childhood acute lymphoblastic leukemia. Pediatr Blood Cancer. (2007) 49:975-81. doi: 10.1002/pbc.21091

7. Söntgerath R, Wulftange M, Eckert K. Kraftdefizite während und nach Krebserkrankungen im Kindes- und Jugendalter - eine systematische Übersichtsarbeit. Bewegungsther Gesundheitssport. (2014) 30:151-61. doi: 10.1055/s-0034-1384425

8. Ness KK, Kaste SC, Zhu L, Pui C-H, Jeha S, Nathan PC, et al. Skeletal, neuromuscular and fitness impairments among children with newly diagnosed acute lymphoblastic leukemia. Leukemia Lymphoma. 56:1004-11. doi: 10.3109/10428194.2014.944519

9. Campbell KL, Winters-Stone KM, Wiskemann J, May AM, Schwartz AL, Courneya KS, et al. Exercise guidelines for cancer survivors: consensus statement from international multidisciplinary roundtable. Med Sci Sports Exerc. (2019) 51:2375-90. doi: 10.1249/MSS.0000000000002116

10. Baumann FT, Bloch W, Beulertz J. Clinical exercise interventions in pediatric oncology: a systematic review. Pediatr Res. (2013) 74:366-74. doi: $10.1038 /$ pr.2013.123

11. Braam K, van der Torre P, Takken T, Veening M, van Dulmen-den Broeder E, Kaspers G. Physical exercise training interventions for children and young adults during and after treatment for childhood cancer. Cochr Database Syst Rev. (2016) 3:CD008796. doi: 10.1002/14651858.CD008796.pub3

12. Morales JS, Valenzuela PL, Rincon-Castanedo C, Takken T, Fiuza-Luces C, Santos-Lozano A, et al. Exercise training in childhood cancer: a systematic review and meta-analysis of randomized controlled trials. Cancer Treat Rev. (2018) 70:154-67. doi: 10.1016/j.ctrv.2018.08.012

13. Pocock SJ, Simon R. Sequential treatment assignment with balancing for prognostic factors in the controlled clinical trial. Biometrics. (1975) 103-15. doi: $10.2307 / 2529712$

14. Beenakker E, Van Der Hoeven J, Fock J, Maurits N. Reference values of maximum isometric muscle force obtained in 270 children aged 416 years by hand-held dynamometry. Neuromusc Disord. (2001) 11:441-6. doi: 10.1016/S0960-8966(01)00193-6

15. Stuberg WA, Metcalf W. Reliability of quantitative muscle testing in healthy children and in children with Duchenne muscular dystrophy using a handheld dynamometer. Phys Therapy. (1988) 68:977-82. doi: 10.1093/ptj/68.6.977 of the manuscript and Elias Dreismickenbecker for his support as a research assistant during the revision process. This publication uses data collected within the framework of the $\mathrm{PhD}$ thesis entitled Effekte eines kombinierten Ausdauer- und Krafttrainings auf die Muskelkraft während der Intensivtherapie in der pädiatrischen Onkologie: Ergebnisse einer randomisiert kontrollierten Studie of SS at the faculty German Sport University in Cologne (2019).
16. Brussock CM, Haley SM, Munsat TL, Bernhardt DB. Measurement of isometric force in children with and without Duchenne's muscular dystrophy. Phys Therapy. (1992) 72:105-14. doi: 10.1093/ptj/72.2.105

17. Stark T, Walker B, Phillips JK, Fejer R, Beck R. Hand-held dynamometry correlation with the gold standard isokinetic dynamometry: a systematic review. PM R. (2011) 3:472-9. doi: 10.1016/j.pmrj.2010.10.025

18. Vaidya T, Beaumont M, de Bisschop C, Bazerque L, Le Blanc C, Vincent A, et al. Determining the minimally important difference in quadriceps strength in individuals with COPD using a fixed dynamometer. Int J Chron Obstruct Pulmon Dis. (2018) 13:2685-93. doi: 10.2147/COPD.S161342

19. Geiger R, Strasak A, Treml B, Gasser K, Kleinsasser A, Fischer V, et al. Sixminute walk test in children and adolescents. J Pediatr. (2007) 150:395-9.e392. doi: 10.1016/j.jpeds.2006.12.052

20. Gulmans V, Van Veldhoven N, De Meer K, Helders P. The sixminute walking test in children with cystic fibrosis: reliability and validity. Pediatr Pulmonol. (1996) 22:85-89. doi: 10.1002/(SICI)10990496(199608)22:2<85::AID-PPUL1>3.0.CO;2-I

21. Li A, Yin J, Yu C, Tsang T, So H, Wong E, et al. The six-minute walk test in healthy children: reliability and validity. Eur Respir J. (2005) 25:1057-60. doi: 10.1183/09031936.05.00134904

22. Norman K, Stobäus N, Pirlich M, Bosy-Westphal A. Bioelectrical phase angle and impedance vector analysis-clinical relevance and applicability of impedance parameters. Clin Nutr. (2012) 31:854-61. doi: 10.1016/j.clnu.2012.05.008

23. Nagano M, Suita S, Yamanouchi T. The validity of bioelectrical impedance phase angle for nutritional assessment in children. J Pediatr Surg. (2000) 35:1035-9. doi: 10.1053/jpsu.2000.7766

24. Dittmar M. Reliability and variability of bioimpedance measures in normal adults: effects of age, gender, and body mass. Am J Phys Anthropol. (2003) 122:361-70. doi: 10.1002/ajpa.10301

25. Jung M, Höhne A, Varni J, Klingebiel T, Landenberger M. Die Messung von Fatigue in der pädiatrischen Onkologie - Die "PedsQL 3.0 Multidimensional Fatigue Scale" in einer ersten deutschen Version. Kinder Jugendmedizin. (2008) 8:453-7. doi: 10.1055/s-0038-1629061

26. Ravens-Sieberer U, Bullinger M. Assessing health-related quality of life in chronically ill children with the German KINDL: first psychometric and content analytical results. Qual Life Res. (1998) 7:399-407. doi: 10.1023/A:1008853819715

27. Opper E, Worth A, Wagner M, Bös K. Motorik-Modul (MoMo) im Rahmen des Kinder-und Jugendgesundheitssurveys (KiGGS). Bundesgesundheitsblatt Gesundheitsforschung Gesundheitsschutz. (2007) 50:879-88. doi: 10.1007/s00103-007-0251-5

28. Götte M, Kesting S, Winter C, Rosenbaum D, Boos J. Comparison of self-reported physical activity in children and adolescents before and during cancer treatment. Pediatr Blood Cancer. (2014) 61:1023-8. doi: $10.1002 / \mathrm{pbc} .24898$

29. Mahon AD, Marjerrison AD, Lee JD, Woodruff ME, Hanna LE. Evaluating the prediction of maximal heart rate in children and adolescents. Res Quar Exerc Sport. (2010) 81:466-71. doi: 10.1080/02701367.2010.10599707

30. Borg G. Anstrengungsempfinden und körperliche Aktivität. Deutsches Ärzteblatt. (2004) 101:1016-21.

31. Devereaux J. Comparison of rates of perceived exertion between active video games and traditional exercise. Int SportMed J. (2012) 13:133-40.

32. Groslambert A, Mahon AD. Perceived exertion. Sports Med. (2006) 36:911-28. doi: 10.2165/00007256-200636110-00001 
33. Fröhlich M, Pieter A, Gießing J, Klein M, Strack A, Felder H, et al. Kraft und Krafttraining bei Kindern- und Jugendlichen - aktueller Stand. Zeitschrift Leistungssport. (2009) 2:1-23.

34. Medicine, A. C., and o.S. (2009). American College of Sports Medicine position stand. Progression models in resistance training for healthy adults. Med Sci Sports Exerc. 41:687. doi: 10.1249/MSS.0b013e3181915670

35. Boudreaux BD, Hebert EP, Hollander DB, Williams BM, Cormier CL, Naquin MR, et al. Validity of wearable activity monitors during cycling and resistance exercise. Med Sci Sports Exerc. (2018) 50:624-33. doi: 10.1249/MSS.0000000000001471

36. Pittler M, Blümle A, Meerpohl J, Antes G. CONSORT 2010: Aktualisierte Leitlinie für Berichte randomisierter Studien im Parallelgruppen-Design. Deutsc Med Wochenschrift. (2011) 136:e20-3. doi: 10.1055/s-0031-12 72980

37. Data-Input (2005). Das B.I.A.-Kompendium 3. Ausgabe (C. Darmstadt: Digitaldruck Darmstadt GmbH \& Co. KG.

38. Fiuza-Luces C, Padilla JR, Soares-Miranda L, Santana-Sosa E, Quiroga JV, Santos-Lozano A, et al. Exercise intervention in pediatric patients with solid tumors: the physical activity in pediatric cancer trial. Med Sci Sports Exerc. (2017) 49:223-30. doi: 10.1249/MSS.0000000000001094

39. Braam KI, van Dijk-Lokkart EM, Kaspers GJ, Takken T, Huisman J, Bierings $\mathrm{MB}$, et al. Cardiorespiratory fitness and physical activity in children with cancer. Support Care Cancer. (2015) 24:2259-68. doi: 10.1007/s00520-015-2993-1

40. Redelmeier DA, Bayoumi AM, Goldstein RS, Guyatt GH. Interpreting small differences in functional status: the Six Minute Walk test in chronic lung disease patients. Am J Respir Crit Care Med. (1997) 155:1278-82. doi: 10.1164/ajrccm.155.4.9105067

41. McNeely ML, Courneya KS. Exercise programs for cancer-related fatigue: evidence and clinical guidelines. J Natl Compr Cancer Netw. (2010) 8:945-53. doi: 10.6004/jnccn.2010.0069

42. Zdolsek HJ, Lindahl OA, Sjöberg F. Non-invasive assessment of fluid volume status in the interstitium after haemodialysis. Physiol Meas. (2000) 21:211. doi: 10.1088/0967-3334/21/2/301

43. Jungblut SA, Frickmann H, Zimmermann B, Muller U, Bargon J. [The effects of physical training on the body composition of patients with COPD]. Pneumologie. (2009) 63:374-9. doi: 10.1055/s-0029-1214713

44. Souza M, Tomeleri C, Ribeiro A, Schoenfeld B, Silva A, Sardinha L, et al. Effect of resistance training on phase angle in older women: A randomized controlled trial. Scand J Med Sci Sports. (2017) 27:1308-16. doi: $10.1111 /$ sms. 12745

45. Campa F, Silva AM, Toselli S. Changes in phase angle and handgrip strength induced by suspension training in older women. Int J Sports Med. (2018) 39:442-9. doi: 10.1055/a-057 4-3166

46. Cunha PM, Tomeleri CM, Nascimento MAD, Nunes JP, Antunes M, et al. Improvement of cellular health indicators and muscle quality in older women with different resistance training volumes. J Sports Sci. (2018) 36:2843-8. doi: 10.1080/02640414.2018.1479103

47. Reimers C, Mersch S, Müller-Nothmann S-D. Die Bioelektrische Impedanzanalyse (BIA). Methoden zur Messung der Körperkompartimente in der Ernährungsmedizin Schweizerische Zeitschrift für Ganzheitsmedizin/Swiss. J Integr Med. (2005) 17:355-61. doi: $10.1159 / 000281984$

48. Gupta D, Lis CG, Dahlk SL, King J, Vashi PG, Grutsch JF, et al. The relationship between bioelectrical impedance phase angle and subjective global assessment in advanced colorectal cancer. Nutr J. (2008) 7:19. doi: 10.1186/1475-2891-7-19

49. Bauer J, Jürgens H, Frühwald MC. Important aspects of nutrition in children with cancer. Adv Nutr Int Rev J. (2011) 2:67-77. doi: 10.3945/an.110.000141

50. Gaynor EP, Sullivan PB. Nutritional status and nutritional management in children with cancer. Arch Dis Child. (2015) 100:1169-72. doi: 10.1136/archdischild-2014-306941

51. Cramp F, James A, Lambert J. The effects of resistance training on quality of life in cancer: a systematic literature review and meta-analysis. Support Care Cancer. (2010) 18:1367-76. doi: 10.1007/s00520-010-0904-z

52. Eckert K, Rueegg CS, Kesting S, Köppel M, Feißt S, Wittke T, et al. Fatigue und körperliche Aktivität bei an Krebs erkrankten Kindern. Onkologische Pflege Aktuell. (2018) 2:40-6.

53. Lam KKW, Li WHC, Chung OK, Ho KY, Chiu SY, Lam HS, et al. An integrated experiential training programme with coaching to promote physical activity, and reduce fatigue among children with cancer: A randomised controlled trial. Patient Educ Couns. (2018) 101:1947-56. doi: 10.1016/j.pec.2018. 07.008

54. Bower JE. Cancer-related fatigue-mechanisms, risk factors, and treatments. Nat Rev Clin Oncol. (2014) 11:597-609. doi: 10.1038/nrclinonc. 2014.127

55. Wallek S, Senn-Malashonak A, Vogt L, Schmidt K, Bader P, Banzer W. Impact of the initial fitness level on the effects of a structured exercise therapy during pediatric stem cell transplantation. Pediatr Blood Cancer. (2018) 65:e26851. doi: $10.1002 /$ pbc. 26851

Conflict of Interest: The authors declare that the research was conducted in the absence of any commercial or financial relationships that could be construed as a potential conflict of interest.

Copyright (C) 2020 Stössel, Neu, Wingerter, Bloch, Zimmer, Paret, Malki, Baumann, Russo, Henninger, Lehmann, Otto and Faber. This is an open-access article distributed under the terms of the Creative Commons Attribution License (CC BY). The use, distribution or reproduction in other forums is permitted, provided the original author(s) and the copyright owner(s) are credited and that the original publication in this journal is cited, in accordance with accepted academic practice. No use, distribution or reproduction is permitted which does not comply with these terms. 